EPJ Web of Conferences 92,02081 (2015)

DOI: 10.1051/epjconf/ 20159202081

(C) Owned by the authors, published by EDP Sciences, 2015

\title{
Experimental investigation of cavitation in pump inlet
}

\author{
Roman Sikora ${ }^{1}$, Adam Bureček $^{1}$, Lumír Hružík $^{1}$, and Martin Vašina ${ }^{1, a}$ \\ ${ }^{1}$ VŠB-Technical University of Ostrava, Faculty of Mechanical Engineering, Department of Hydromechanics and Hydraulic \\ Equipment, 70833 Ostrava, Czech Republic
}

\begin{abstract}
The article deals with experimental research of cavitation development in inlet tube of hydraulic pump. The pressures in inlet and outlet tube of the pump and flow rate were measured. Mineral oil was used as working fluid. The cavitation was visually evaluated in transparent inlet tube. The inlet tube underpressure was achieved by throttle valve. The relationship between the generation of bubbles and the inlet pressure is evaluated.
\end{abstract}

\section{Introduction}

Cavitation is the formation of cavities (bubbles) in oil at the local pressure drop, followed by their implosion. The pressure drop may be caused by the local increase of speed. Cavitation bubbles are initially filled with vacuum, and later with vapour of surrounding oil or the gases that can diffuse from the surrounding oil. When the underpressure disappears, the bubbles collapse and form shock waves with destructive effect on the surrounding material. Cavitation causes noise, reduces machine efficiency and can cause the mechanical damage too. The cavitation is affected mainly by the size of underpressure, cohesion (surface tension) of oil and temperature [1,2].

Dissolved air in oil has significant influence on bubbles formation. It is in form of chemical bond of nitrogen and oxygen molecules. The amount of dissolved air can be estimated on basis of the Henry's law [3]:

$$
V_{D A}=k \cdot V_{L} \cdot \frac{p}{p_{a}},
$$

where $V_{D A}$ volume of dissolved air, $\mathrm{m}^{3} ; V_{L}$ volume of oil, $\mathrm{m}^{3} ; p_{a}$ atmospheric pressure, $\mathrm{Pa} ; p$ absolute pressure of oil, $\mathrm{Pa} ; k$ absorption coefficient ( $k \cong 0.093 \div 0.1$ for oil/air mixture) .

Amount of dissolved air is slightly dependent on temperature. But in the temperature range $t=(20 \div 80){ }^{\circ} \mathrm{C}$, this dependence could be neglected [3]. When a steady-state is changed either by change of pressure or temperature, the new bubbles are formed or disappear. This process depends on the air dissolving time in oil that is much longer compared to the time of air release from oil.

\footnotetext{
${ }^{\mathrm{a}}$ Corresponding author: martin.vasina@vsb.cz
}

The flow of oil/air mixture could be considered as two-phase flow and described by the following equations $[4,5]$ :

1. Continuity equation for single component $\mathrm{N}$ (either oil or air) of mixture:

$$
\frac{\partial\left(\rho_{N} \cdot \alpha_{N}\right)}{\partial t}+\frac{\partial\left(\rho_{N} \cdot j_{N i}\right)}{\partial x_{i}}=I_{N} .
$$

2. Equation of motion for single component of mixture:

$$
F_{N k}^{T}=\frac{\partial\left(\rho_{N} \cdot \alpha_{N} \cdot u_{N k}\right)}{\partial t}+\frac{\partial\left(\rho_{N} \cdot \alpha_{N} \cdot u_{N i} \cdot u_{N k}\right)}{\partial x_{i}}
$$

where $\rho_{N}$ density of $\mathrm{N}$-th component (oil; air), $\mathrm{kg} \mathrm{m}^{-3}$; $\alpha_{N}$ volume fraction of $\mathrm{N}$-th component, $1 ; u_{N k}$ velocity of $\mathrm{N}$-th component in direction $k, \mathrm{~m} \mathrm{~s}^{-1} ; t$ time, $\mathrm{s}$; $x_{i}$ coordinate, $\mathrm{m} ; I_{N}$ the ratio of the mass transfer into the component $\mathrm{N}$ from the other ingredients per unit volume, $1 ; F^{T}{ }_{N k}$ total force on component $\mathrm{N}$ in direction $k, \mathrm{~N}$.

3. Energy equation, which is given by the first law of thermodynamics and is in general very complex for multiphase flow.

Prepared equipment will be primarily used to verify the monitoring possibility of the multi-phase flow, especially of oil/air mixture. 


\section{Description of equipment}

The schematic diagram of the experimental equipment for investigation of cavitation is displayed in figure 1.

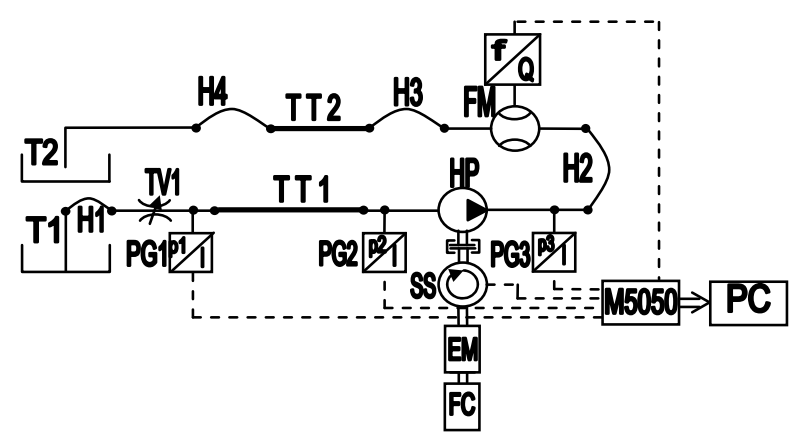

Figure 1. Scheme of experimental equipment.

The legend of the used hydraulic elements (see figure 1) is the following:

T1, T2 - Tanks; H1, H2, H3, H4 - Hoses; TV1 Throttle valve; PG1, PG2, PG3 - Pressure gauges; TT1, TT2 - Transparent tubes; HP - Hydraulic pump; SS - Speed sensor; EM - Electric motor; FC Frequency convertor; FM - Flow meter; M5050 Hydrotechnik universal measuring device; PC Computer.

The lower tank content is $100 \mathrm{dm}^{3}$ and the upper tank content is $40 \mathrm{dm}^{3}$. Measuring range of the pressure gauges PG1 and PG2 is $(-1 \div 6)$ bar and in case of the pressure gauge $\mathrm{PG} 3$ the range is $(0 \div 60)$ bar. There is used the gear hydraulic pump with the geometric volume $V_{G}=5 \mathrm{~cm}^{3}$. The pump is driven by asynchronous electric motor with frequency convertor. The maximum speed of electric motor is $3000 \mathrm{rpm}$ and the motor power is $1500 \mathrm{~W}$. The geometric volume of gear flow meter $V_{G}=2.22 \mathrm{~cm}^{3}$ and its measuring range is $(0.7 \div 70) \mathrm{dm}^{3} \cdot \mathrm{min}^{-1}$. Flexible hoses are $1 \mathrm{~m}$ long. Mineral oil with the kinematic viscosity $v=32 \mathrm{~mm}^{2} \cdot \mathrm{s}^{-1}$ at the temperature $40{ }^{\circ} \mathrm{C}$ was used for investigation. The length of the tube TT1 in the pump inlet was $700 \mathrm{~mm}$ and the tube TT2 in the outlet was $450 \mathrm{~mm}$ long. The inner diameter of each tube was $20 \mathrm{~mm}$ with the wall thicknesses $t=5 \mathrm{~mm}$.

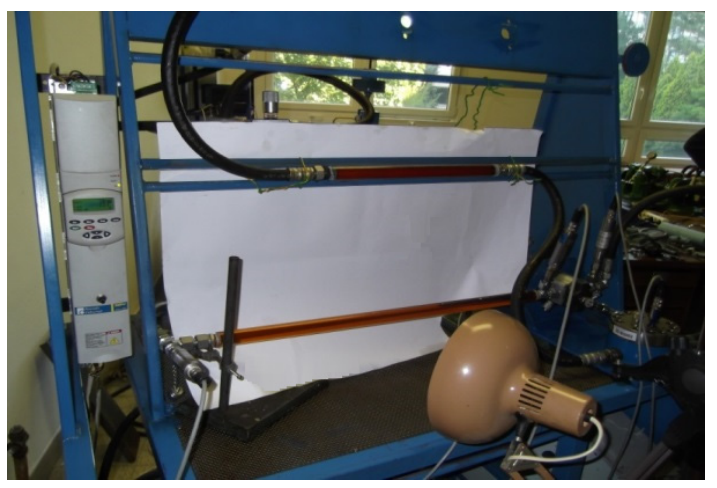

Figure 2. Experimental equipment.
The measuring device M5050 Hydrotechnik was used to data collection (see figure 3 ).

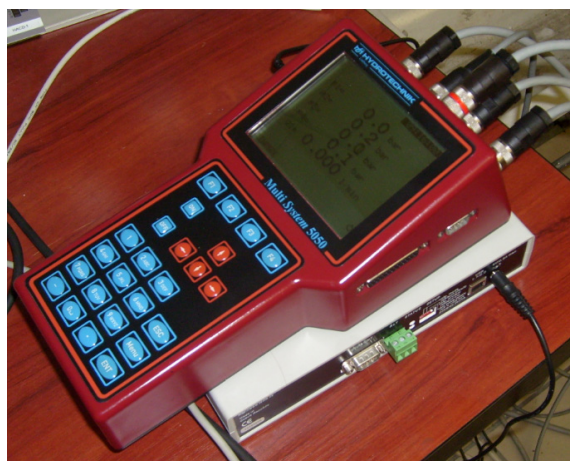

Figure 3. M5050 Hydrotechnik.

\section{Description of work}

Mineral oil is sucked from the tank T1 through the throttle valve TV1 and flows through the transparent tube TT1 to the hydraulic pump HP. The pump pushes oil through the flow meter FM, the second transparent tube TT2 to the upper tank T2. The throttle valve TV1 is used to pressure control. The pressure drops cause the release of air bubbles from the oil. The pressures on both ends of the tube TT1 are measured and the amount of bubbles is observed at the same time. The flow of bubbles through the tubes is recorded by camera for further evaluation.

The revolutions of the electric motor are controlled by frequency convertor. For this reason the flow rate is changed too.

\section{Results}

The evaluation of flow was based on observation of bubbles formation and on measuring of pressures and flow rate. The formation of first bubbles depending on the inlet pressure $p_{1}$ can be seen in the photographs. The photographs in figure 4 are taken for nominal rpm 500 and various inlet pressures.

$$
p_{1}=-0.301 \mathrm{bar}
$$

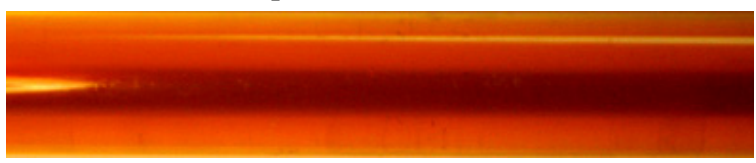

$$
p_{1}=-0.502 \text { bar }
$$

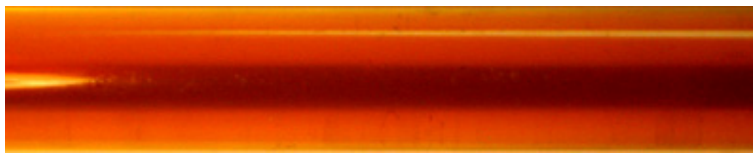

$$
p_{1}=-0.707 \text { bar }
$$

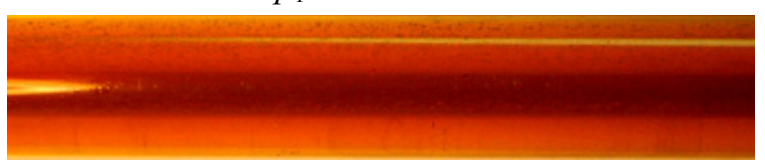




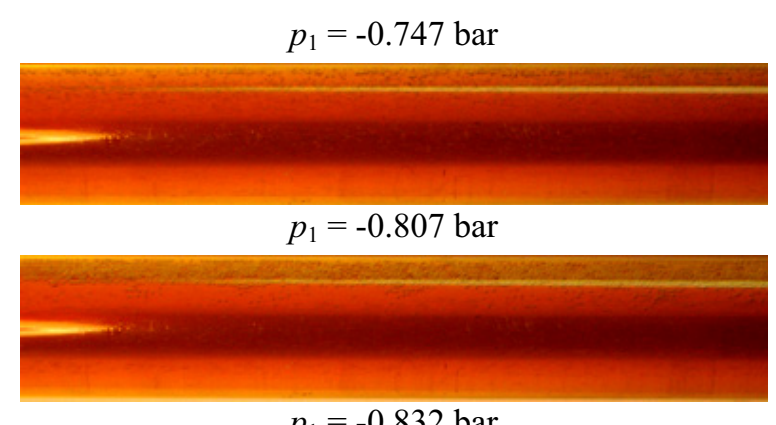

$p_{1}=-0.832$ bar

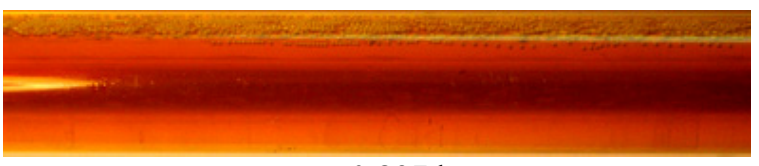

$p_{1}=-0.897$ bar

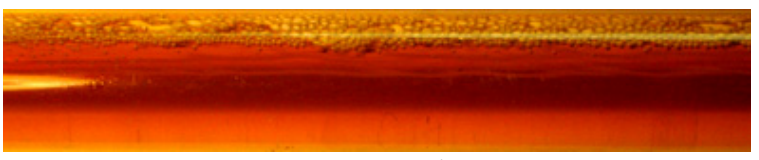

$p_{1}=-0.922$ bar

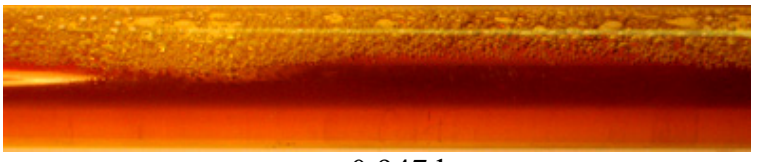

$p_{1}=-0.947$ bar

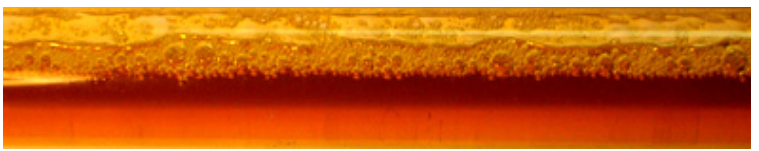

Figure 4. Transparent tube TT1.

The bubbles formation is clearly visible in figure 5. All pressures are presented as pressures relative to atmospheric pressure.

$\mathrm{rpm} 500, p_{1}=-0.502$ bar

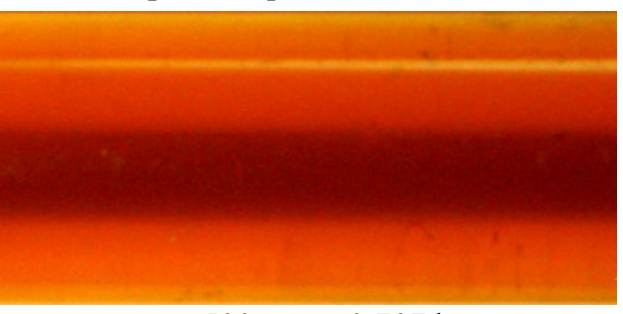

$\operatorname{rpm} 500, p_{1}=-0.707$ bar

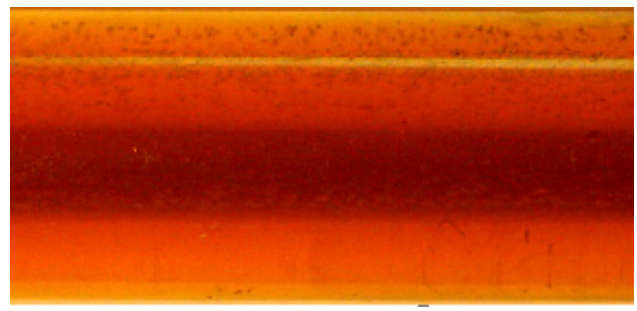

$\operatorname{rpm} 500, p_{1}=-0.947$ bar

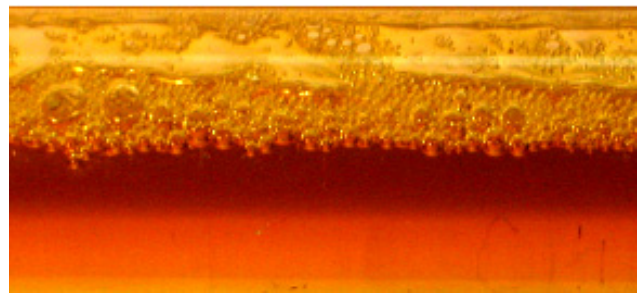

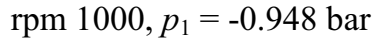

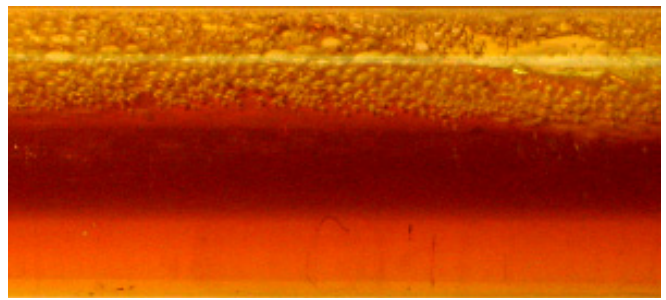

Figure 5. Detail of the transparent tube TT1.

The formation of first visible bubbles could be seen from the photographs at the pressure $p_{1} \cong-0.7$ bar. It is possible to investigate the bubbles quantity, further the size and shape of the bubbles. The figure shows that at faster flow approximately the same relative volume of bubbles arose, but the bubbles are smaller.

It is necessary to determine the coefficient $I_{N}$ in the continuity equation (2) in order to make the mathematical model of the flow, which can be considered as two-phase flow. The observation of flow along the tube TT1 would make possible to determine it. Volume fraction of oil component could be determined by measuring of the flow rate.

Another possibility is to monitor the dependence of the flow rate on the inlet pressure $p_{1}$. The dependence was measured for various rpm of the motor and thus for various flow rates. Individual measurements lasted for 5 seconds with the sampling frequency $f=10 \mathrm{~Hz}$ at a constant speed. The flow rate was controlled by the throttle valve TV1.

As can be seen from the figures $6-8$, there is a significant decrease in the flow rate, when the pressure $p_{1}$ is about -0.8 bar. The flow rate decrease may be considered as the beginning of bubble formation. Therefore it is possible to determine the start of their formation. The advantage of measuring of the flow rate decreases is that it is possible to determine this value quantitatively.

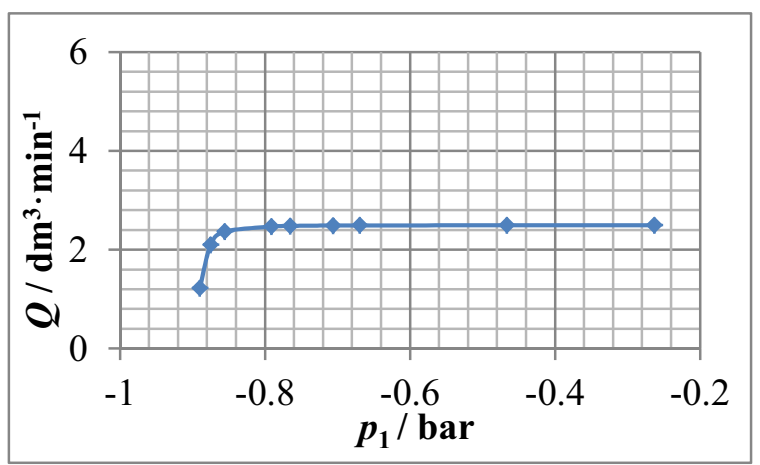

Figure 6. Dependence of flow rate $Q$ on pressure $p_{1}$ for nominal rpm 500 . 


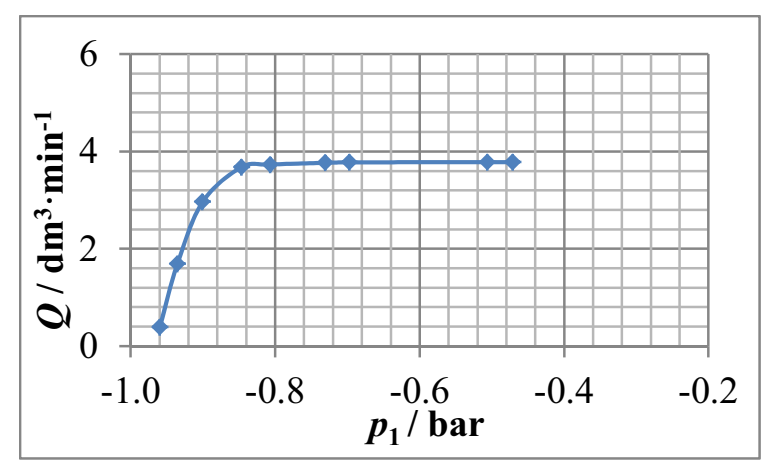

Figure 7. Dependence of flow rate $Q$ on pressure $p_{1}$ for nominal rpm 750.

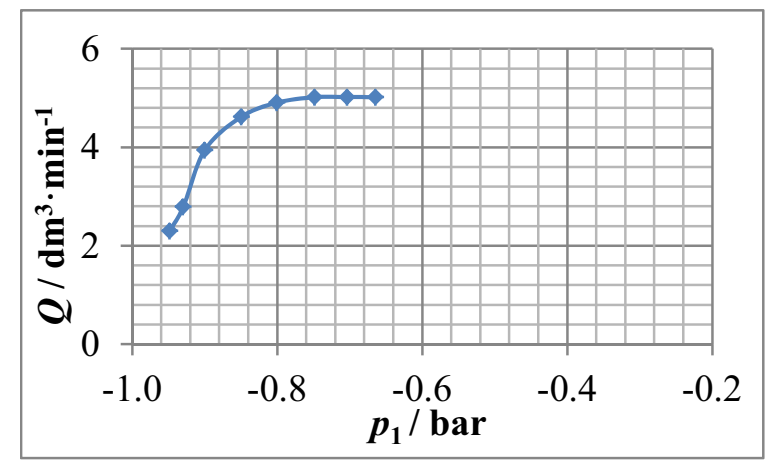

Figure 8. Dependence of flow rate $Q$ on pressure $p_{1}$ for nominal rpm 1000.

Compared to the visual observation (see figures 4,5) of the transparent tube TT1, the observable decrease of the flow rate is evident. There is a more significant pressure drop.

It is not possible to use the outlet pressure $p_{3}$ dependence on the flow rate as there is not significant break point, which could be considered as the start of bubble formation. The pressure $p_{3}=(0.4 \div 1.5)$ bar measured at the pump outlet depends on the pressure loss of the flow meter, discharge piping and hoses.

Enlarging of air bubbles was observed along transparent tube TT1 during the measurement. This enlarging is caused by higher pressure $p_{1}$ on the tube inlet in comparison with the pressure $p_{2}$ on its outlet. Measurement of the pressure gradient could be used to research of air bubbles behaviour along the tube TT1.

\section{Conclusions}

The special equipment was designed in order to investigate the formation and behaviour of bubbles in hydraulic circuits. Measurement of flow rate and pressures at several points of the circuit and camera were used to obtain information about the flow and to capture the initial formation of bubbles. The measurements proved that using of this equipment for required task is convenient.

It could be seen that the photos show a start of bubbles formation while the flow rate decrease can be observed in case of larger air volume.
In future it could be verified bubbles behaviour along the tube from its beginning to the end and in the discharge. For the investigation of flow behaviour in the discharge will be used another transparent tube TT2 and the throttle valve will be added to the discharge.

\section{Acknowledgements}

This paper has been elaborated in the framework of the project Opportunity for young researchers, reg. no. CZ.1.07/2.3.00/30.0016, supported by Operational Programme Education for Competitiveness and co-financed by the European Social Fund and the state budget of the Czech Republic.

The work presented in this paper was also supported by a grant SGS "Zkoumání dynamiky hydraulického vedení" SP2014/208.

\section{References}

1. E. E. Michaelides, Particles, Bubbles \& Drops: Their Motion, Heat and Mass Transfer. Singapore: World Scientific, 410 (2006)

2. J. Jablonská, EPJ Web of Conferences, EFM13, Compressibility of the fluid, 67, 02048, (2014)

3. A. Bureček, Fluid Structure Interaction in Case of Non-Stationery Flow, $\mathrm{PhD}$ thesis, VSB-TU OSTRAVA, 121, (2013)

4. N. Kolev, Multiphase Flow Dynamics 2: Mechanical and Thermal Interactions. Berlin: Springer, 692 (2002)

5. C. E. Brennen, Fundamentals of multiphase flow. New York: Cambridge University Press, 345 (2005) 